\title{
VISÕES DE SUSTENTABILIDADE DOS ATORES DA CADEIA PRODUTIVA DOS PRODUTOS FLORESTAIS NÃO-MADEIRÁVEIS
}

\author{
Osmar Siena \\ Doutor em Engenharia de Produção pela Universidade Federal de Santa Catarina - UFSC \\ Professor do Mestrado em Administração da Universidade Federal de Rondônia - UNIR \\ osmar_siena@uol.com.br
}

Carlos André da Silva Müller

Doutor em Economia Aplicada pela Universidade Federal de Viçosa - UFV Professor do Mestrado em Administração da Universidade Federal de Rondônia - UNIR profcarlosmuller@yahoo.com.br

\author{
Dirlei Terezinha Fachinello \\ Mestre em Administração pela Universidade Federal de Rondônia - UNIR \\ Professora do Instituto Federal de Educação, Ciência e Tecnologia do Acre - IFAC \\ dirleifac@yahoo.com.br
}

\begin{abstract}
RESUMO
Este artigo analisa a concepção de extrativismo e as visões de sustentabilidade e a relação entre estas e visões ambientalistas dos atores da cadeia produtiva dos produtos do extrativismo florestal não-madeirável no estado de Rondônia (Brasil). Na base teórica do trabalho, são discutidas as vertentes ambientalistas, as visões e dimensões de sustentabilidade. A coleta de dados foi realizada por meio de entrevistas. Foram consultados cento e quarenta e cinco atores da cadeia dos produtos florestais não-madeiráveis (PFNM). Esta pesquisa adotou a abordagem qualitativa e o principal método utilizado foi a análise de conteúdo. As mensagens contidas nas entrevistas foram confrontadas com as categorias das vertentes ambientalistas e as visões de sustentabilidade. Constatou-se que a concepção de extrativismo tradicional não é mais predominante. Na perspectiva institucional, predomina a visão de sustentabilidade na concepção empresarial; na perspectiva econômica prevalece a visão de sustentabilidade que representa os pressupostos defendidos pela economia ambiental. Em termos de vertentes ambientalistas, predomina a concepção sustentabilista. Concluiu-se que o baixo valor agregado dos produtos e a precárias condições de vida têm influenciado os atores da cadeia do PFNM a enunciar perspectivas conservadoras, com pouca preocupação ambiental.
\end{abstract}

Palavras-chave: Ambientalismo; Extrativismo; PFNM; Sustentabilidade.

\begin{abstract}
The economy of the state of Rondônia has been supported by timber and mineral extraction. Agribusiness, especially in cattle, is their main economic activity. A considerable part of its territory is protected area, among which are the extractive reserves, where an extractive economy remains, whose products are sold without any added value and low use of technologies. This article examines the concept of extractivism and visions of sustainability and the relationship between these and environmentalists' visions of the actors of the supply chain of non-timber forest products in the state of Rondônia (Brazil). On the basis of theoretical work, this paper discusses the environmentalists' slopes and the views and dimensions of sustainability. The research adopted a qualitative approach and the main method used was content analysis. Data collection was conducted through interviews and we consulted one hundred forty-five actors in the chain of non-timber forest products (NTFPs) of native forest. The messages contained in the interviews were compared with the representative categories of environmental and sustainability visions. It was found that the traditional concept of extraction is no longer dominant. The vision of sustainability in the conception business dominates in the institutional perspective. In the economic perspective, the vision of sustainability representing assumptions defended by environmental economics prevails. In terms of environmentalists' slopes, the predominant conception is sustainabilist. It was concluded that the low value-added products and poor living conditions have influenced the actors in the chain of NTFPs to articulate conservative outlook, with little environmental concern.
\end{abstract}

VISIONS OF SUSTAINABILITY OF ACTORS OF SUPPLY CHAIN FOREST PRODUCTS OF NON-TIMBER

Keywords: Extrativism; NTFP; Sustainability; Environmentalism.

Revista de Gestão Social e Ambiental - RGSA, São Paulo, v. 6, n. 1, p. 53-69, jan./abril 2012. 


\section{INTRODUÇÃO}

No Brasil, a partir do final da década de 1980, em resposta às pressões de movimentos e de órgãos nacionais e internacionais, particularmente em relação à proteção da Amazônia, ações são desenvolvidas com o objetivo de minimizar ou compensar a busca pela acumulação de riqueza a elevados custos ambientais. Foram instituídas ilhas de floresta primária pela criação de outras Unidades de Conservação (UC), como a Reserva Extrativista (Resex), uma categoria de UC que visa conciliar preservação ambiental com presença humana (Cavalcanti, F., 2002).

Diversos autores apontam que o processo de criação das Resex foi influenciado pela aliança dos seringueiros e povos indígenas com ambientalistas e organizações não-governamentais (ONGs) nacionais e internacionais, contando com apoio de pesquisadores brasileiros que se uniram às demandas dos primeiros (Alegretti, 1997; 2008; Gonçalves, 2001; 2003; Almeida, 2004). Santilli (2005) acrescenta que a criação das Resexs é parte, ainda, de uma corrente do ambientalismo que se consolida, o socioambientalismo, cuja influência tem sido crescente. Assim, por meio do Sistema Nacional de Unidades de Conservação (SNUC), a política ambiental e a legislação brasileira incorporaram a "[...] proposta de preservação com a presença do homem, como fruto de um movimento político dos seringueiros acreanos, em resposta à tentativa de expropriação da terra e ao processo de derrubada da floresta." (Cavalcanti, F., 2002, p.2).

O estado de Rondônia já teve sua economia apoiada no extrativismo madeireiro e mineral. Atualmente tem o agronegócio, especialmente o gado de corte, como sua principal atividade econômica. Em contrapartida, parte de seu território é de área de preservação legalmente instituída, sendo 25 Reservas Extrativistas, ocupando uma área 1,7 milhões de hectares, que corresponde a 7,15\% da superfície do Estado (GTA, 2008).

Nas RESEX de Rondônia, e em seus entornos, bem como em áreas ribeirinhas a rios e igarapés, existem populações que desenvolvem atividade extrativa vegetal. Os produtos oriundos desse extrativismo, em boa parte, são comercializados sem agregação de valor e com baixa utilização de tecnologias. Sendo os produtos de baixo valor agregado, as comunidades e os produtores familiares enfrentam também os desafios da concorrência de produtos domesticados. Por isso, do ponto de vista econômico, há críticas contundentes ao extrativismo na Amazônia, como a de Homma (2000; 2008), segundo o qual, o setor extrativo compreende um ciclo econômico de três fases distintas: na primeira, há o aumento da extração e crescimento da demanda; na segunda, a capacidade da oferta chega ao limite devido ao custo de extração com o aumento da área de coleta e; na terceira, a extração começa a declinar devido a oferta de produto domesticado, desde que existam tecnologia e viabilidade econômica. A domesticação anula, segunda essas críticas, as condições de competir por parte da extração primária. Assim, apenas se o mercado permanecer modesto, o setor extrativo sobrevive (Homma, 2008).

Sob o ponto de vista ambiental, as críticas também são contundentes. Para Pádua (2007), por exemplo, as Resexs não têm nenhuma vinculação com a conservação, pois foram criadas apenas para fins sociais e econômicos e que a atividade dominante em muitas dessas áreas não é mais o extrativismo e ela denomina o modelo de Resex de "reforma agrária branca", destacando que o processo de criação dessas UCs é fruto da união entre seringueiros e ambientalistas como mera estratégia para assegurar o direito à posse das áreas por eles habitadas historicamente. De forma semelhante se manifesta Olmos (2007), segundo o qual existe fartura de estudos comprovando a "extinção em massa" de espécies em Resex.

Outros especialistas, como Allegretti (2008), defendem que a política de criação de áreas protegidas para o uso sustentável é exitosa, pois, do ponto de vista político, criou meios para resolução de conflitos em torno da terra e da floresta; em termos sociais, garantiu meios para as gerações; ambientalmente, impediu o avanço do desmatamento; e, culturalmente, respeitou formas tradicionais de uso dos recursos.

Desse modo, tanto a crítica na perspectiva econômica e ambiental quanto a defesa do modelo remetem à necessidade de compreender qual a contribuição da atividade extrativa para a

Revista de Gestão Social e Ambiental - RGSA, São Paulo, v. 6, n. 1, p. 53-69, jan./abril 2012. 
Amazônia e suas diversas regiões na perspectiva do desenvolvimento sustentável. Para tanto é fundamental ter em conta qual ou quais visões de sustentabilidade são apropriadas pelos atores envolvidos. Compreender esta questão é fundamental, uma vez que existe diversidade de possibilidades de entendimento e interpretação; há diferentes formas de apropriação do conceito. Diante deste contexto, a pesquisa que deu origem a este artigo visou prospectar quais as visões de sustentabilidade de atores da cadeia produtiva dos produtos florestais não-madeiráveis (PFNM) no estado de Rondônia, bem como identificar o que entendem por extrativismo e por desenvolvimento.

São considerados produtos florestais não-madeiráveis aqueles de origem biológica diferente de madeira, derivados da floresta, áreas florestadas e árvores isoladas (Fao, 1999). Neste artigo, o foco está restrito aos produtos de origem de floresta nativa.

Neste trabalho, apesar das diferenças conceituais (Kemp e Martens, 2007; Sneddon, 2009), os termos sustentabilidade e desenvolvimento sustentável são usados de modo intercambiáveis, considerando que ainda não é predominante a distinção na produção acadêmica sobre o tema, assim como a sociedade em geral tende a tratá-los como sinônimos.

\section{FUNDAMENTAÇÃO TEÓRICA}

Uma questão que influencia, de forma decisiva, na concepção e disseminação do que vem a ser sustentabilidade é a visão de mundo dos envolvidos.

Gladwin, Kennelly e Krause (1995), mesmo reconhecendo o emaranhado de visões, afirmam ser possível identificar alguns componentes que são mais compartilhados pela maioria das concepções de sustentabilidade. Para os referidos autores, desenvolvimento sustentável possui os seguintes componentes (ou requisitos): é um processo de busca de desenvolvimento humano (ampliando o leque de escolhas das pessoas) em uma sociedade inclusiva (desenvolvimento do sistema humano e sistema ambiental ao longo do tempo), conectada (interdependência ecológica, social e econômica), equitativa (intergeracional, intrageracional e entre as espécies), prudente (dever do cuidado e prevenção científica, política e tecnológica) e segura (prevenção contra ameaças crônicas e perturbações). Os referidos autores confrontam esses componentes com três visões de mundo ou paradigmas: tecnocêntrico convencional, ecocêntrico e o Sustaincentric, cujos pressupostos são apresentados na figura 1 .

\begin{tabular}{|l|l|l|l|}
\hline Alguns pressupostos & Tecnocentrismo & Sustaincentrism & Ecocentrismo \\
\hline \multicolumn{5}{|c|}{ A. Ontológico e Ético } \\
\hline Metáfora da terra & Grande máquina & Suporte à vida & Mãe/ teia da vida \\
\hline Composição do sistema & Atomístico/partes & Partes e todo & Orgânico/todo \\
\hline Estrutura do sistema & Hierárquico & Holárquico & Heterárquico \\
\hline Homem e natureza & Dissociados & Interdependentes & Indissociados \\
\hline Valor da natureza & Antropocentrismo & Inerente & Intrínseco \\
\hline Escala tempo/espaço & Pequeno/próximo & Multiescala & Indefinido \\
\hline \multicolumn{5}{|c|}{ B. científico e tecnológico } \\
\hline Resiliência da natureza & Resistente/robusta & Variável/frágil & Altamente vulnerável \\
\hline Capacidade de carga & Sem limites & Limitada & Excedida \\
\hline Tamanho da população & Sem problemas & Estabilização rápida & Congelar/reduzir \\
\hline Severidade dos problemas & Trivial & Consequêncial & Catastrófico \\
\hline Crença na tecnologia & Otimismo & Ceticismo & Pessimismo \\
\hline Capital humano x natural & Substituição total & Substituição parcial & Complementares \\
\hline \multicolumn{5}{|c|}{ C. econômico e psicológico } \\
\hline Objetivos primários & Alocação eficiente & Qualidade de vida & Integridade ecológica \\
\hline
\end{tabular}

Revista de Gestão Social e Ambiental - RGSA, São Paulo, v. 6, n. 1, p. 53-69, jan./abril 2012. 
Visões de sustentabilidade dos atores da cadeia produtiva dos produtos florestais não-madeiráveis

\begin{tabular}{|l|l|l|l|}
\hline Estrutura econômica & Livre mercado & Economia verde & Estado estacionário \\
\hline Papel do crescimento & Bom/necessário & Misto/modificar & Ruim/eliminar \\
\hline Alívio da pobreza & Crescimento & $\begin{array}{l}\text { Iguais } \\
\text { oportunidades }\end{array}$ & Redistribuição \\
\hline Capital natural & $\begin{array}{l}\text { Aproveitar/transform } \\
\text { ar }\end{array}$ & Conservar/manter & Elevar/expandir \\
\hline Orientação do mercado & Global & Nacional & Biorregional \\
\hline
\end{tabular}

Figura 1: Paradigmas ambientais.

Fonte: Adaptado de Gladwin, Kennelly e Krause, 1995, p. 883.

Ao confrontar as características dos três paradigmas, Gladwin, Kennelly e Krause (1995) concluem que apenas o Sustaincentrism satisfaz os requisitos de sustentabilidade, pois o tecnocentrismo falha no atendimento dos cinco requisitos propostos e o ecocentrismo, embora mais integrativo, não atende aspectos decisivos.

Outra fonte de influência para formação do conceito de sustentabilidade são as visões e/ou concepções institucionais. Nesta perspectiva, podem ser identificados grupos que influenciaram a construção e disseminação do conceito de sustentabilidade. Entre eles estão: World Commission on Environment and Development (WCED, 1987) - Relatório Nosso Futuro Comum, International Institute of Environment and Development (IIED, 2001) e World Business Council for Sustainable Development - WBCSD (Mebratu, 1998). Na figura 2 consta uma síntese da posição institucional de sustentabilidade.

\begin{tabular}{|l|l|l|l|l|}
\hline \multicolumn{2}{|c|}{ Visão institucional } \\
\hline Instituição & \multicolumn{1}{|c|}{ Solução } & \multicolumn{1}{|c|}{ Epicentro solução } & \multicolumn{1}{c|}{$\begin{array}{c}\text { Plataforma de } \\
\text { solução }\end{array}$} & \multicolumn{1}{c|}{ Liderança } \\
\hline WCED & Consenso político & $\begin{array}{l}\text { Crescimento } \\
\text { sustentável }\end{array}$ & Estado-Nação & $\begin{array}{l}\text { Governos e Organizaçães } \\
\text { Internacionais }\end{array}$ \\
\hline IIED & $\begin{array}{l}\text { Desenvolvimento } \\
\text { rural }\end{array}$ & $\begin{array}{l}\text { Cuidado ambiental } \\
\text { primário }\end{array}$ & Comunidades & $\begin{array}{l}\text { ONGs Nacionais e } \\
\text { Internacionais }\end{array}$ \\
\hline WBCSD & Interesse empresarial & Ecoeficiência & $\begin{array}{l}\text { Indústrias e } \\
\text { empresas }\end{array}$ & Liderança corporativa \\
\hline
\end{tabular}

Figura 2: Visão institucional do conceito sustentabilidade.

Fonte: Mebratu, 1998, p. 504-506.

Todas as visões institucionais têm como elemento central a definição de desenvolvimento sustentável dada pela Comissão Brundtland e o conceito de "satisfação das necessidades", sendo que as diferenças de interpretação são decorrentes das influências dos objetivos das instituições.

O movimento ambientalista também exerceu e exerce importante influência tanto na construção quanto na difusão de concepções e conceitos de sustentabilidade. Como movimento organizado, entretanto, o ambientalismo surgiu no século XIX, nos Estados Unidos, em defesa da natureza intocada, dando origem a uma corrente de pensamento denominada de preservacionista ou "culto ao silvestre" como a designa Martinez-Alier (2007) ou conservacionismo clássico na perspectiva de Colchester (2000). Como a visão conservacionista é de uma natureza selvagem e frágil, necessitando ser intocada e isolada da permanência humana, essa vertente defende a existência de espaços de natureza original, livres da influência do mercado e da presença humana. Compõe essa corrente a ecologia profunda que considera o ser humano apenas parte da natureza e não pode arbitrar valor ao restante do mundo natural (Pepper, 2000).

A sustentabilista, a segunda corrente, surge em torno das concepções de ecoeficiência e modernização ecológica, preocupada com o crescimento econômico, particularmente com seus

Revista de Gestão Social e Ambiental - RGSA, São Paulo, v. 6, n. 1, p. 53-69, jan./abril 2012. 
impactos no meio ambiente e na saúde humana; ou seja, defende o crescimento econômico, mas não a qualquer custo (Martinez-Alier, 2007). Essa vertente teve por base inicial os métodos de manejo florestal científico, pois a linha de atuação de seus adeptos é a defesa da exploração racional dos recursos e o combate ao desperdício e à poluição industrial (Martinez-Alier, 2007).

A terceira vertente ou concepção ambientalista, denominada socioambientalista, surge da discordância dos movimentos sociais com as perspectivas anteriores e, em aliança com ambientalistas, passaram a defender a possibilidade de conciliar preservação ambiental e permanência das populações tradicionais em seus territórios. Essa vertente se contrapõe tanto ao modelo de natureza intocada, que não reconhece direitos às populações das terras tradicionalmente ocupadas por famílias (Colchester, 2000), quanto a defesa da modernização ecológica. Diegues (2000) denomina os movimentos das populações locais contra a destruição da floresta Amazônica de "ambientalismo camponês". Para Martinez-Alier (2007), essa abordagem está no âmbito da ecologia política e que em sua base estão as questões sobre conflitos distributivos dos custos e benefícios da utilização ou preservação dos recursos naturais. As visões ambientalistas e paradigmas ambientais estão sintetizadas na figura 3.

\begin{tabular}{|c|l|c|}
\hline $\begin{array}{c}\text { Vertentes } \\
\text { ambientalistas }\end{array}$ & \multicolumn{1}{|c|}{ Visões } & \multicolumn{1}{|c|}{$\begin{array}{c}\text { Paradigmas } \\
\text { ambientais }\end{array}$} \\
\hline Preservacionista & $\begin{array}{l}\text { Natureza selvagem e frágil, } \\
\text { Natureza intocada e objeto de proteção total, } \\
\text { Ação contra o avanço da economia industrial. }\end{array}$ & \multicolumn{1}{|c|}{ Ecocêntrico } \\
\hline Socioambientalista & $\begin{array}{l}\text { Ecologia política, Etnoconservação e justiça ambiental. } \\
\text { Defesa da mudança de paradigma na relação homem- } \\
\text { natureza, nas políticas ambientais e na distribuição de } \\
\text { recursos. } \\
\text { Reconhecimento da sustentabilidade do manejo } \\
\text { tradicional. }\end{array}$ & $\begin{array}{c}\text { Sustaincentric, mas } \\
\text { com algumas } \\
\text { características do } \\
\text { ecocêntrico }\end{array}$ \\
\hline Sustentabilista & $\begin{array}{l}\text { Ecoeficiência e modernização ecológica. } \\
\text { Defesa da exploração racional dos recursos. } \\
\text { Ação de integração: natureza e economia. }\end{array}$ & $\begin{array}{c}\text { Sustaincentric, mas } \\
\text { com algumas } \\
\text { características do } \\
\text { tecnocêntrico }\end{array}$ \\
\hline Necnocêntrico \\
\hline
\end{tabular}

Figura 3: Visões ambientalistas e paradigmas ambientais.

Fonte: Elaborado com base em Pearce et al, 1993, Becker (1994), Veiga (2006; 2008) MartinezAlier (2007), Colchester (2000) e Diegues (2000).

Na perspectiva econômica, também é possível distinguir visões distintas e/ou divergentes de sustentabilidade. São várias as maneiras de interpretar a questão. Uma delas é a partir dos fundamentos que alicerçam a relação sociedade e ambiente em termos gerais. Sob este enfoque é possível identificar algumas perspectivas que estão entre dois extremos: no primeiro, a economia convencional, com pressupostos no crescimento econômico sem limites, baseados na exploração dos recursos naturais percebidos como infinitos; no outro, a ecologia profunda, tendo por base a igualdade das espécies e como postulado a restrição ao crescimento econômico e populacional para os objetivos de preservação da natureza (Becker, 1994). Entre os dois extremos podem-se identificar outras abordagens: economia neoclássica, que postula resolver a crise considerando que o ambiente é subestimado, usado em demasia e degradado (Pearce et al., 1993); “[...]a economia política do ambiente[...]" postulando que a questão ambiental tem característica essencialmente 
social e política (Becker, 1994) e; ecologia social, que defende a possibilidades de conciliar a visão reducionista da economia com a visão holística da ecologia profunda como forma de superar o dualismo existente (Mebratu, 1998; Veiga, 2006, 2008). Evidentemente que várias vertentes econômicas, ambientais, políticas e científicas foram desenvolvidas nos grupos que compuseram ou compõem cada uma dessas concepções.

Assim, a ideia de sustentabilidade pode ser encontrada nos escritos dos economistas clássicos: Malthus defendeu que a terra impunha limite absoluto ao crescimento populacional devido a sua capacidade de carga (a ideia de escassez absoluta); Ricardo também concluiu que os recursos alimentares diminuiriam progressivamente no tempo, em razão da redução da qualidade da terra, levando a um decréscimo do retorno marginal (escassez relativa); Mill enfatizou o conceito de estado estacionário que é um princípio chave na moderna literatura sobre sustentabilidade (Patterson, 2002). A razão principal pela qual essas predições são criticadas é bem conhecida: elas subestimaram a capacidade da tecnologia de utilizar de maneira mais eficiente os recursos.

No século XX, os chamados neomalthusianos colocaram em cheque a ideia de crescimento ilimitado, questão assumida pelo Clube de Roma, em 1969, para quem havia a necessidade da estagnação do aumento populacional e do crescimento industrial diante da limitação dos recursos naturais. A publicação da obra de Meadows et al. (27), Os Limites do Crescimento, foi uma atualização das ideias Malthusianas sobre a relação sociedade ambiente.

Numa outra vertente, um grupo de pensadores, entre eles Esther Boserup, acredita nos meios tecnológicos como solução para o problema do crescimento populacional e da degradação do meio ambiente. Nesta visão, que poderia ser chamada cornucopiana, o aumento da população é um estímulo às inovações e técnicas que provocam sempre melhorias na agricultura para aumentar a produção de alimentos e promover bem-estar humano (Valadão; Siena, 2010):

[...] Portanto, a menos que as importações líquidas de produtos alimentares estejam aumentando, parte da força de trabalho rural deve ser empregada em investimentos de capital, em desmatamentos e outras melhorias, sejam de investimentos de trabalho do produtor e seus dependentes ou investimentos rentabilizados. (Boserup, 1991, p. 33).

De modo geral, as concepções de sustentabilidade oriundas da economia têm por base, essencialmente, a possibilidade dos componentes humanos e ecossistema serem substituídos um pelo outro. Em outros termos, as variantes da concepção são influenciadas pela posição assumida em relação à substituição entre trabalho, capital e recursos naturais ou como preferem alguns autores, substituição entre os diversos tipos de capitais: capital humano, construído, natural e (adotados por outros) social. Essas aproximações têm sido classificadas como "sustentabilidade fraca" e "sustentabilidade forte" (Amazonas, 2002; Veiga, 2006).

$\mathrm{Na}$ "sustentabilidade fraca", a preocupação é com o capital total, no qual as partes podem ser substituídas e o bem-estar do ecossistema poderia declinar desde que o bem-estar humano aumentasse pelo menos o equivalente. A formulação tem por base a chamada "economia da poluição" que considera os danos ambientais como externalidades negativas, gerando custo social, devendo este ser internalizado nos cálculos do agente gerador, atingindo um nível socialmente ótimo de poluição (Amazonas, 2002). Para esta vertente, a sustentabilidade pode ser entendida como a maximização do bem-estar humano (maximização da utilidade pela alocação eficaz dos recursos) ao longo do tempo. Para os defensores da "sustentabilidade forte", a base está no reconhecimento da necessidade de transferência de um estoque de capital natural constante entre as gerações; o pressuposto é a manutenção das partes e do todo em boas condições, mantido o capital natural, ou a parte essencial dele, constante (Amazonas, 2002).

Para Cavalcanti C. (2010, p. 56), como às vezes se torna importante para o modelo convencional, ele até considera o meio ambiente, mas como apêndice da economia; este é o campo

Revista de Gestão Social e Ambiental - RGSA, São Paulo, v. 6, n. 1, p. 53-69, jan./abril 2012. 
da chamada economia ambiental (ou visão econômica da economia, como sugere o referido autor), cujo "[...] foco é encontrar preços corretos para a alocação ótima de recursos [...] com uma motivação central: internalizar custos ambientais a fim de se obterem preços que reflitam os custos de oportunidade sociais marginais completos.". Como não é possível considerar o meio ambiente inexistente ou como algo externo ao sistema (apêndice), tanto a visão convencional quanto a visão da economia ambiental não são adequadas como arcabouços. Este tipo de constatação agravou o enfrentamento entre sociedade e natureza, economia e meio ambiente, economia convencional e ecologia convencional: enquanto a primeira lida apenas com espécie humana, considerando o ecossistema uma externalidade, a segunda se ocupa de todas as espécies, menos a humana (Cavalcanti, C., 2010).

A busca pela superação dessa visão dicotômica de mundo foi uma das razões para o surgimento da chamada Economia Ecológica (EE), classificada na sua origem como "Ciência e Gestão da sustentabilidade" (Constanza, 1991) ou "Economia Socioambiental" (Veiga, 2007). Entre as questões centrais para a EE estão: a compreensão das interações meio ambiente e economia, sendo esta última uma parte ou um subsistema da natureza, submetendo-se a este; a economia é um sistema aberto dentro do ecossistema (Cavalcanti, C., 2010); conflitos desafiam a tendência à valoração puramente monetária de situações essenciais para a vida humana; e incomensurabilidade de valores frente ao econômico (Martínez-Alier, 2007, p. 23 apud Cavalcanti, C., 2010).

Amazonas (2002) destaca que a economia ecológica reconhece que o avanço tecnológico propicia condições para superar limites naturais em busca de maior eficiência e a substituição de recursos exauríveis e que o avanço tecnológico ocorre dentro de certos limites fisicamente possíveis. Assim, diz Amazonas, a economia ecológica adota uma posição de "ceticismo prudente", procurando delimitar as escalas em que restrições podem constituir limites às atividades.

Para Cavalcanti C. (2010) é possível imaginar uma escala que vai do ecológico ao econômico: nos extremos estariam a economia e a ecologia. Próxima da economia, mais ao centro, estaria a economia ambiental e próxima da ecologia, a economia ecológica. Para o referido autor, a economia ambiental trata os problemas ecológicos com "[...] as ferramentas da economia neoclássica."; seu propósito é internalizar o meio ambiente no cálculo econômico, valorizando-o monetariamente, permitindo "[...] aos preços a condição de refletir valores hipotéticos para serviços e funções da natureza.”; a EE, por sua vez, “[...] tem como propósito dizer em que medida o uso da natureza pode ser feito sustentavelmente." (p. 60-61).

Cavalcanti C. (2010, p. 63) resume a discussão sobre as concepções de sustentabilidade das vertentes econômicas nos seguintes termos:

[...]a economia convencional exclui a natureza como externalidade do processo econômico; a economia ambiental se preocupa em dar preço à natureza, com a tendência de vê-la como amenidade (uma ideia implícita na noção vulgar do "verde"); e a economia ecológica atribui à natureza a condição de suporte insubstituível de tudo o que a sociedade pode fazer.

A figura 4 apresenta uma síntese das características dessas abordagens econômicas e as relações com vertentes ambientalistas e paradigmas ambientais.

\begin{tabular}{|l|l|c|c|}
\hline $\begin{array}{c}\text { Vertentes } \\
\text { Econômicas }\end{array}$ & \multicolumn{1}{|c|}{ Visões de Sustentabilidade } & $\begin{array}{c}\text { Vertentes } \\
\text { Ambientalistas }\end{array}$ & $\begin{array}{c}\text { Paradigmas } \\
\text { Ambientais }\end{array}$ \\
\hline Cornucopiana & $\begin{array}{l}\text { Crescimento ilimitado. } \\
\text { visão panglossiana da vida. } \\
\text { Recursos tecnológicos como solução. } \\
\text { Aumento da população incentiva as }\end{array}$ & Nãontalista & \\
\hline
\end{tabular}

Revista de Gestão Social e Ambiental - RGSA, São Paulo, v. 6, n. 1, p. 53-69, jan./abril 2012. 


\begin{tabular}{|c|c|c|c|}
\hline & inovações. & & \\
\hline Neomalthusiana & $\begin{array}{l}\text { Estagnação do aumento populacional e da } \\
\text { produção. } \\
\text { Teoria do crescimento zero. } \\
\text { Redução de materiais e fluxos de energia. }\end{array}$ & Preservacionista & Ecocêntrico \\
\hline $\begin{array}{l}\text { Economia } \\
\text { Convencional/ } \\
\text { Neoclássica } \\
\end{array}$ & $\begin{array}{l}\text { Exclui a natureza como externalidade do } \\
\text { processo econômico. }\end{array}$ & Não-ambientalista & Tecnocêntrico \\
\hline $\begin{array}{c}\text { Economia } \\
\text { Neoclássica/ } \\
\text { Ambiental }\end{array}$ & $\begin{array}{l}\text { Capital total constante. } \\
\text { "Economia da poluição". } \\
\text { Danos ambientais como externalidades } \\
\text { negativas. } \\
\text { Internalização do custo social. } \\
\text { Nível socialmente ótimo de poluição. } \\
\text { "Sustentabilidade Fraca". }\end{array}$ & Sustentabilista & $\begin{array}{c}\text { Tecnocêntrico } \\
\text { (predominante) } \\
\text { com } \\
\text { características } \\
\text { do } \\
\text { Sustaincentric }\end{array}$ \\
\hline $\begin{array}{l}\text { Economia } \\
\text { Ecológica }\end{array}$ & $\begin{array}{l}\text { Princípio da prudência. } \\
\text { Regular a desigualdade de acesso aos } \\
\text { benefícios diretos e indiretos do uso dos } \\
\text { recursos ambientais e naturais. } \\
\text { Capital total constante - Capital natural } \\
\text { constante. } \\
\text { Sustentabilidade Forte. }\end{array}$ & $\begin{array}{c}\text { Sustentabilista } \\
\text { Socioambientalista } \\
\text { (predominantes) } \\
\text { com características } \\
\text { da } \\
\text { Conservacionista }\end{array}$ & $\begin{array}{c}\text { Sustaincentric } \\
\text { (predominante) } \\
\text { com } \\
\text { características } \\
\text { do } \\
\text { Ecocêntrico }\end{array}$ \\
\hline
\end{tabular}

Figura 4: Visões de sustentabilidade na perspectiva econômica, vertentes ambientalistas e paradigmas ambientais.

Fonte: Elaboração dos autores.

Para Nobre e Amazonas (2002), a ideia de sustentabilidade tem como centro a consideração ética de perpetuação, pois há um desejo intrínseco do ser humano de perpetuação da humanidade e da vida. Assim, para a maioria das vertentes econômicas, a questão essencial é da "utilização ética" dos recursos naturais, pois estes devem ser utilizados para a perpetuação da humanidade e para que a vida não seja ameaçada (Zapparoli et al., 2010).

Reconhecendo a necessidade de reduzir as ambiguidades e, ao mesmo tempo, tornar o conceito mais compreensível para usuários, outros especialistas propõem pensar sustentabilidade em termos de suas dimensões e/ou critérios, usualmente considerando ao menos três dimensões (econômica, social e ambiental). Nesta direção, autores como Sachs (1994; 2002; 2004) e Guimarães (1997) destacam a necessidade de compreender essas dimensões, seus critérios e os objetivos visados, conforme síntese exposta na figura 5.

\begin{tabular}{|l|l|l|}
\hline \multicolumn{4}{|c|}{ As dimensões da sustentabilidade } \\
\hline \multicolumn{1}{|c|}{ Dimensão } & \multicolumn{1}{|c|}{ Critérios } & Objetivos \\
\hline $\begin{array}{l}\text { Sustentabilidade } \\
\text { social }\end{array}$ & $\begin{array}{l}\text { Emprego com qualidade de vida; produção de } \\
\text { bens dirigida prioritariamente às necessidades } \\
\text { básicas sociais; igualdade de acesso aos } \\
\text { serviços sociais; e, justa distribuição de renda. }\end{array}$ & $\begin{array}{l}\text { Reduzir as desigualdades } \\
\text { sociais }\end{array}$ \\
\hline Sustentabilidade & $\begin{array}{l}\text { Implementação de gestão eficiente a fim de } \\
\text { reduzir as diferenças regionais; garantia da }\end{array}$ & $\begin{array}{l}\text { Aumentar a produção e a } \\
\text { riqueza social com }\end{array}$ \\
\hline
\end{tabular}

Revista de Gestão Social e Ambiental - RGSA, São Paulo, v. 6, n. 1, p. 53-69, jan./abril 2012. 


\begin{tabular}{|c|c|c|}
\hline econômica & $\begin{array}{l}\text { segurança alimentar; modernização dos } \\
\text { instrumentos de produção; autonomia na } \\
\text { pesquisa científica e tecnológica; fluxo de } \\
\text { investimentos públicos e privados; absorção } \\
\text { dos custos ambientais. }\end{array}$ & autonomia \\
\hline $\begin{array}{l}\text { Sustentabilidade } \\
\text { ambiental }\end{array}$ & $\begin{array}{l}\text { Respeito à capacidade de carga dos } \\
\text { ecossistemas e a capacidade da natureza para } \\
\text { absorver e recuperar-se das agressões. }\end{array}$ & $\begin{array}{l}\text { Melhorar a qualidade } \\
\text { ambiental. }\end{array}$ \\
\hline $\begin{array}{l}\text { Sustentabilidade } \\
\text { ecológica }\end{array}$ & $\begin{array}{l}\text { Produzir respeitando os ciclos ecológicos dos } \\
\text { ecossistemas; prudência no uso de recursos } \\
\text { naturais não-renováveis; redução da } \\
\text { intensidade energética e aumento da } \\
\text { conservação de energia; e, processos } \\
\text { produtivos de baixo índice de resíduos. }\end{array}$ & $\begin{array}{l}\text { Preservar o potencial do } \\
\text { capital natural. }\end{array}$ \\
\hline $\begin{array}{l}\text { Sustentabilidade } \\
\text { territorial (ou espacial) }\end{array}$ & $\begin{array}{l}\text { Respeito à capacidade de suporte da natureza, } \\
\text { cotejamento entre crescimento econômico, } \\
\text { taxas de aumento de produtividade e } \\
\text { crescimento populacional, sua composição } \\
\text { etária e outras variáveis demográficas; } \\
\text { desconcentração espacial (de atividades; de } \\
\text { população) e relação cidade/campo equilibrada } \\
\text { (benefícios centrípetos). }\end{array}$ & $\begin{array}{l}\text { Melhorar o ambiente urbano } \\
\text { e rural e superação das } \\
\text { disparidades, evitando o } \\
\text { excesso de aglomerações. }\end{array}$ \\
\hline $\begin{array}{l}\text { Sustentabilidade política } \\
\text { e cultural }\end{array}$ & $\begin{array}{l}\text { Construção da cidadania. } \\
\text { Manutenção da diversidade e integração } \\
\text { nacional ao longo do tempo; respeito aos } \\
\text { direitos das minorias; soluções adaptadas a } \\
\text { cada ecossistema; e, respeito à formação } \\
\text { cultural comunitária. }\end{array}$ & $\begin{array}{l}\text { Incorporar os indivíduos ao } \\
\text { processo de } \\
\text { desenvolvimento. Equilíbar } \\
\text { respeito à tradição e } \\
\text { inovação, autonomia e } \\
\text { autoconfiança. }\end{array}$ \\
\hline
\end{tabular}

Figura 5: Dimensões e critérios de sustentabilidade.

Fonte: Elaborado pelos autores com base em Sachs (1994; 2002; 2004) e Guimarães (1997).

Portanto, são várias as visões ou concepções que podem ser identificadas sobre o conceito de sustentabilidade ou desenvolvimento sustentável. Apesar da grande aceitação após a publicação do Relatório Nosso Futuro Comum, cada grupo o interpreta a partir de suas perspectivas e/ou de acordo com seus interesses. Talvez esta seja justamente a razão do aparente consenso. Todos almejam a sustentabilidade, mas o acordo sobre como alcançá-la continua distante.

\section{PROCEDIMENTOS DE COLETA E ANÁLISE DE DADOS}

A pesquisa desenvolvida adotou a abordagem qualitativa e o principal método utilizado foi à análise de conteúdo, na forma proposta por Bardin (2004, p.37), para quem esse tipo de análise é “[...] um conjunto de técnicas de análise das comunicações visando obter [...] conteúdos de mensagens [...] que permitam a inferência de conhecimentos relativos às condições de produção/recepção (variáveis inferidas) destas mensagens.". Assim, o método enfatiza o conteúdo da mensagem, permitindo a utilização da comunicação oral e escrita para investigação de indicadores que permitam a geração de conhecimentos. Por se tratar de uma técnica que pode fazer uso de outras técnicas para alcançar seus objetivos, a análise de conteúdo é também conhecida como método de pesquisa. Entre as técnicas que podem ser utilizadas simultaneamente para realização da análise de conteúdo, Bardin (2004) cita a análise categorial, de avaliação, da enunciação, da expressão e das relações. 
A população foi constituída dos atores envolvidos com extração, comercialização, processamento, distribuição e consumo de PFNM em todas as regiões de produção expressiva de PFNM no estado de Rondônia, baseados na classificação feita pelo Imazon (2008), com adaptação à realidade estudada. A amostra envolveu atores representantes da cadeia produtiva dos PFNM dos municípios de Porto Velho, Guajará-Mirim, Costa Marques e Machadinho do Oeste, no estado de Rondônia, que são regiões onde se concentram grandes áreas de Unidades de Conservação do estado e são as maiores produtoras. Foram entrevistados a 144 (cento e quarenta e quatro) atores, assim distribuídos: 48 produtores (extrativistas); 15 intermediários, 14 representantes de organizações públicas, 19 de organizações não-governamentais, 13 representantes de indústrias ou processadores, 18 representantes do varejo e 18 consumidores.

As amostras de extrativistas, intermediários, varejo e consumidores foram acidentais e por acessibilidade aos locais de extração, intermediação e venda no varejo. Foi consultado o maior número possível de representantes das organizações (de apoio, de fomento, de produtores, etc.) e das indústrias apontadas como importantes no contexto dos PFNM no estado de Rondônia.

Os entrevistados foram instados a falar livremente o que entendem ou o que significa para eles "extrativismo", "desenvolvimento" e "sustentabilidade", sem que o entrevistador fizesse qualquer tipo de esclarecimento.

Para realização da análise de conteúdo numa perspectiva qualitativa, foram adotadas, como categorias iniciais, as visões e dimensões de sustentabilidade e vertentes ambientalistas identificadas na literatura. Cada entrevista com os atores da cadeia produtiva constituiu a unidade de contexto. As unidades de registro foram selecionadas a partir da vinculação entre os itens componentes das características das categorias identificadas. As porções de texto que compõem cada unidade de registro foram confrontadas com as categorias mencionadas. Em termos operacionais, a análise foi realizada pela utilização do sistema Sphinx (software), cujos recursos técnicos permitem e facilitam este tipo de análise (Freitas e Moscarola, 2010).

\section{RESULTADOS E DISCUSSÃO}

O conceito de extrativismo parece estar passando por um período de transformação em sua concepção. A visão romântica, como "Possibilidade de viver em contato com a natureza.", não tem mais prevalecido. Os extrativistas (coletores) tendem considerar o extrativismo como meio de vida, uma maneira de garantir a sobrevivência da família, enquanto os respondentes vinculados à industria o consideram como meio para gerar emprego e aumentar renda, demonstrado uma posição muito menos de concílio homem-natureza do que a ideia concebida a priori. Os representantes do varejo, dos consumidores e das organizações não-governamentais foram os que mais associaram a atividade extrativa como atividade econômica com preservação ambiental ainda que modesta, conforme declaração de um dos consultados: "[...] alternativa de renda e manter a floresta preservada.".

Embora uma parte dos atores ainda tenha a visão do extrativismo tradicional, caracterizado como simples coleta de recursos florestais, inviável economicamente, conforme preconiza Homma (2008), contata-se uma tendência de mudança de concepção com a incorporação de novas formas de compreender a atividade.

O neoextrativismo, que "[...] promove um salto de qualidade pela incorporação do progresso técnico e envolve novas alternativas de extração de recursos associadas com cultivo, criação e beneficiamento da produção." (Rego, 2008. p.3), é identificado em respostas como: "Seria melhor [...] Houvesse estrutura para produção, beneficiamento e armazenamento adequado dos produtos [...]". O agroextrativismo, incentivado pelos movimentos sociais, associações, sindicatos, etc., que defende a incorporação de atividades como a agricultura, criação de pequenos animais, cultivo de árvores frutíferas, pesca etc., combinadas com atividades extrativistas para gerar um sistema

Revista de Gestão Social e Ambiental - RGSA, São Paulo, v. 6, n. 1, p. 53-69, jan./abril 2012. 
complexo de produção em Resex com características de agricultura familiar (Portal do Extrativismo, 2009) também é defendido por uma parte significativa dos respondentes.

De maneira geral, para os atores entrevistados, o desenvolvimento é concebido como crescimento econômico, vislumbrado como alcance de melhoria na educação, na saúde, ter acesso a energia, a estradas asfaltadas, etc., traduzido por alguns entrevistados como melhoria da qualidade de vida. A situação de vulnerabilidade dos extrativistas, vivendo em locais sem infraestrutura básica (transporte, saúde, educação), o baixo preço pago aos produtos extrativistas, aliados à ausência de políticas públicas eficazes justifica a busca pelo aumento da renda a qualquer custo como condição para sobrevivência dos atores da cadeia produtiva dos PFNMs em Rondônia, em especial os extrativistas. As organizações que mantêm um contato mais próximo com os extrativistas demonstram uma preocupação maior com as pessoas e com sua situação econômica do que com o meio ambiente, conforme depoimento de um gestor de Resex: "[...] a sobrevivência do homem é mais importante que a sobrevivência da floresta.".

Em relação às visões de sustentabilidade e vertentes ambientalistas, os resultados estão sintetizados na figura 6.

A concepção institucional reflete a atuação e influência de três grandes grupos cuja atuação influenciou e influencia a forma da sociedade conceber a questão: das organizações governamentais nacionais e internacionais, como as Nações Unidas e agências no âmbito de cada país; das organizações não-governamentais (ONGs); das corporações empresariais representadas pelas suas entidades.

Em relação a essa visão há um predomínio da concepção empresarial nas manifestações dos atores consultados, seguida da governamental e da não-governamental. Esta posição reflete a convicção de que as soluções para problemas ambientais devem ser buscadas no processo produtivo e nas lideranças corporativas (Mebratu, 1998). No contexto em análise, a cadeia produtiva dos PFNM no estado de Rondônia, caracterizada por insipiente agregação de valor aos produtos. A concepção de o processo produtivo como fator relevante para solução de questões ambientais parece refletir o desejo de incorporar à atividade extrativa e aos produtos os avanços técnicos e tecnológicos disponíveis. Quando os dados são analisados por categoria de atores, constata-se esta mesma predominância em todos os elos da cadeia produtiva, com exceto para os intermediários. As organizações e parte dos consumidores estão mais alinhadas à visão ampla governamental traduzida pelo "uso dos recursos, garantindo-as para as gerações futuros",a visão da WCED (1987). Nos discursos analisados, foi também possível identificar a visão não-governamental (ONG) em parte dos extrativistas, além da perspectiva empresarial. 


\begin{tabular}{|c|c|c|c|}
\hline Atores consultados & Visão institucional & Visão econômica & $\begin{array}{l}\text { Vertentes } \\
\text { ambientalistas }\end{array}$ \\
\hline Extrativistas & $\begin{array}{l}\text { Empresarial } \\
\text { não-governamental }\end{array}$ & Economia convencional & Sustentabilista \\
\hline Intermediários & & Economia ecológica & $\begin{array}{l}\text { Preservacionista } \\
\text { Não-Ambientalista }\end{array}$ \\
\hline Indústria & Empresarial & Economia ambiental & $\begin{array}{l}\text { Sustentabilista } \\
\text { Não-Ambientalista }\end{array}$ \\
\hline Varejo & Empresarial & Economia ambiental & $\begin{array}{l}\text { Sustentabilista } \\
\text { Não-Ambientalista }\end{array}$ \\
\hline Org. Governamentais & Governamental & Economia ambiental & $\begin{array}{l}\text { Sustentabilista } \\
\text { Preservacionista }\end{array}$ \\
\hline $\begin{array}{l}\text { Org. } \\
\text { Não-Governamentais }\end{array}$ & Governamental & Economia ambiental & $\begin{array}{l}\text { Socioambientalista } \\
\text { Preservacionista }\end{array}$ \\
\hline Consumidor & $\begin{array}{l}\text { Empresarial } \\
\text { Governamental }\end{array}$ & Economia convencional & Não Ambientalista \\
\hline Todos os Respondentes & Empresarial & Econômica ambiental & Sustentabilista \\
\hline
\end{tabular}

Figura 6: Visões de sustentabilidade dos atores dos PFNM e ambientalismo.

Fonte: Elaborado pelos autores.

Para análise da sustentabilidade na perspectiva econômica, foram consideradas três visões básicas: economia convencional, a qual negligencia a questão do meio ambiente, economia ambiental (sustentabilidade fraca), em que se reconhece o meio ambiente como restrição do desenvolvimento, mas podem a questão social e econômica em primeiro plano, e a economia ecológica (sustentabilidade forte), em que a preservação ambiental é ponto fundamental, estando em igualdade (ou sendo mais importante) do que as questões sociais e econômicas. Cabe salientar as dificuldades de diferenciar algumas posições dos entrevistados quanto à relação com as vertentes econômicas. Alguns discursos apresentaram características que poderiam ser associadas a mais de uma visão.

De acordo com os resultados, a visão predominante nas manifestações de todos os consultados é a da economia ambiental, seguida da economia convencional e economia ecológica, respectivamente. A primeira tem como principais contribuições os atores da indústria, varejo e das organizações governamentais e não-governamentais; a segunda, na visão dos extrativistas e dos consumidores e, a terceira, prevalece na visão dos intermediários. Essa visão sobre a relação sociedade e ambiente na economia ambiental está refletida na posição dos atores consultados quando destacam que a importância do extrativismo está relacionado, essencialmente, com a geração de renda e melhoria das condições de vida dos praticantes, com menos destruição possível. Esta relação sugere a ideia de que possíveis danos ambientais são aceitáveis desde que as condições humanas sejam melhoradas.

Interessante observar que a visão convencional, que desconsidera a questão ambiental é prevalecente na visão dos extrativistas, o que parece um contrassenso em um primeiro momento, posto que é difícil imaginar que coletores possam excluir o meio ambiente na sua forma de ver e atuar no mundo. O resultado talvez possa ser explicado pelo fato de as condições precárias de vida que se encontram; em alguns casos, pobreza extrema e, em outros, totalmente dependentes dos programas governamentais. A luta para obter o mínimo para sobrevivência pode influir significativamente na forma de perceber a questão, dando ênfase quase exclusiva ao aspecto econômico. Outra surpresa é o discurso enunciado pelos intermediários categorizados na Economia Ecológica. Por serem na maioria simples atravessadores que compram o produto dos extrativistas e distribuem para pequenos comerciantes, feirantes ou mesmo pequenas indústrias, esperava-se uma visão mais tradicional. O resultado obtido, talvez, seja decorrente do fato de que essas pessoas ou

Revista de Gestão Social e Ambiental - RGSA, São Paulo, v. 6, n. 1, p. 53-69, jan./abril 2012. 
organizações que representam dependam do fornecimento dos produtos ao longo do tempo, o que pode levar a uma preocupação maior com a preservação ambiental. Por outro lado, a baixa ou nenhuma escolaridade impõe dificuldade natural para expressar verbalmente o que entendem pelo conceito, o que pode causar distorção no resultado.

Em relação ao ambientalismo, a primeira constatação é a de que para a maioria dos grupos consultados há uma combinação: predomínio de uma vertente, mas com presença significativa de outra ou não presença de concepção ambiental. Este último caso foi verificado na visão dos intermediários, representantes das indústrias e do varejo, demonstrando que uma parte insere o meio ambiente na sua forma de lidar com a realidade e outra não. Os representantes das organizações (governamentais e não-governamentais) também se dividiram entre sociambientalistas, na qual se crê que a conciliação homem-natureza é possível, e preservacionistas, que consideram o meio ambiente em primeiro lugar. Este resultado reflete uma reconhecida diferença de posição dos militantes de organizações ambientais: a concordância ou não com a possibilidade de conciliar preservação ambiental e presença humana em Unidades de Conservação (Colchester, 2000; Calvacanti, C., 2002).

Considerados todos os participantes da pesquisa, constatou-se o predomínio da vertente sustentabilista, ou seja, a tecnificação como forma de superar os problemas ambientais, resultado que foi influenciado pela defesa das atividades de manejo florestal madeireiro em Reservas Extrativistas, inclusive pelos representantes das organizações governamentais e nãogovernamentais.

Quando são comparados os resultados sobre vertentes ambientalistas com as visões de sustentabilidade na perspectiva econômica, contata-se uma coerência nas posições expressas pelos consultados. A maioria dos consultados com visão da economia tradicional ou economia ambiental expressa posições associadas às concepções sustentabilista ou ausência de concepção ambiental. Aqueles que expressam uma visão mais próxima das posições defendidas pela economia ecológica podem ser associados à vertente preservacionista.

Em relação às dimensões de sustentabilidade, em termos gerais, a ordem de predominância encontrada foi econômica e social e ambiental (igual importância), ecológica e político cultural. A figura 7 apresenta as dimensões predominantes na visão dos consultados.

\begin{tabular}{lc}
\hline Atores consultados & Dimensões de sustentabilidade \\
\hline Extrativistas & Econômico-Social \\
\hline Intermediários & Econômica \\
\hline Indústria & Econômica \\
\hline Varejo & Econômica \\
\hline Organizações Governamentais & Ambiental - Econômica \\
\hline Organizaçóes Não-Governamentais & Econômico-Social \\
\hline Todos os Respondentes & Econômica \\
\hline
\end{tabular}

Figura 7: Posição dos atores sobre as dimensões de sustentabilidade.

Fonte: Elaborado pelos autores.

A dimensão econômica predomina também para intermediários, varejistas e representantes das indústrias. Ou seja, os representantes dos elos que compõem as cadeias produtivas de produtos florestais não-madeiráveis, exceto extrativistas, são aqueles que dão maior importância à dimensão econômica. Ressalta-se que a maioria da respostas relacionadas a essa dimensão vincula-se aos aspectos econômicos problemáticos da atividade, tal como preço, logística, informação, demanda de mercado, etc. Isto é, ainda que o discurso tenha a dimensão econômica, essa importância está pautada em melhoria das atividades e não numa visão que desconsidere a dimensão ambiental e ecológica.

Revista de Gestão Social e Ambiental - RGSA, São Paulo, v. 6, n. 1, p. 53-69, jan./abril 2012. 


\section{CONSIDERAÇÕES FINAIS}

Este trabalho visou identificar e analisar as visões de sustentabilidade, concepções sobre extrativismo e vertentes ambientalistas dos atores dos produtos do extrativismo florestal nãomadeireiro no estado de Rondônia.

Constatou-se que a concepção de extrativismo puro, ou seja, a simples coleta de produtos naturais na forma tradicional, não é mais predominante. Há uma tendência para a aceitação da prática do neoextrativismo e do agroextrativismo. Na perspectiva institucional, predomina a visão de sustentabilidade na concepção empresarial nas manifestações dos atores consultados, refletindo a posição hegemônica presente numa sociedade capitalista: o mercado, as organizações empresariais e suas lideranças são capazes de oferecer respostas adequadas aos problemas envolvendo sociedade e meio ambiente.

$\mathrm{Na}$ perspectiva econômica, predomina a visão de sustentabilidade que representa os pressupostos defendidos pela economia ambiental.

Não foi encontrado predomínio da visão socioambientalista como era esperado, pois a prática do extrativismo ocorre principalmente no interior das Resexs. Por outro lado, o predomínio da vertente sustentabilista na visão dos atores consultados, está em harmonia com a presença de características do neoextrativistas e com o predomínio da visão da economia ambiental; há confiança na tecnologia e na modernização dos processos produtivos para superação dos problemas ambientais.

Em relação às dimensões de sustentabilidade predomina na visão dos respondentes quanto a dimensão econômica e, num secundo plano, a dimensões social e ambiental, inclusive na visão de representantes de organizações não-governamentais, na maioria presidentes de associações ou cooperativas de produtores.

A política de conservação dos recursos naturais nos últimos anos tem tido avanços na redução de desmatamento e na consolidação uma perspectiva socioambiental cuja prerrogativa é conciliar homem-natureza, ou seja, a manutenção do homem nas áreas protegidas, dada sua tradição de viver nas florestas de forma sustentável. Entretanto, a pesquisa indicou que a falta de agregação de valor dos produtos florestais não-madeiráveis em Rondônia e as precárias condições de vida prevalecente têm levado os extrativistas à procura da satisfação das necessidades básicas, buscando maior renda e infraestrutura, motivo pela qual as visões enunciadas por eles são conservadoras, algumas vezes colocando o econômico em primeiro plano, outras desconsiderando o meio ambiente ou considerando-o como restritivo às suas atividades. Isso influenciou a visão dos atores na concepção da sustentabilidade fraca ou do crescimento econômico convencional, ou seja, o desenvolvimento preconizado é basicamente associação ao crescimento econômico. Esse resultado implica problemas de preservação dos recursos naturais legalmente protegidos, causando pressão sobre as florestas, como, por exemplo, o uso do manejo florestal madeireiro como alternativa de renda em algumas reservas.

A visão institucional empresarial e a vertente ambientalista sustentabilista parece ter também a mesma origem. A perspectiva econômica tradicional ou da sustentabilidade fraca, a visão empresarial de sustentabilidade e o ambientalismo sustentabilista é o reconhecimento de que no ambiente micro, as inovações, seja de produto, de nichos de mercado, ou mesmo de processos devem ocorrer para que as áreas protegidas estejam atendendo as políticas macro de conservação do meio ambiente.

Cabe salientar que as poucas declarações sobre conservação da natureza por parte dos extrativistas, relacionando mais à vivência em Resex como seu meio de vida, denotam a pouca eficácia de organizações que, diretamente, atuam para gerenciamento dessas áreas e reforçam que políticas públicas no nível micro devem ser revisadas para que a sustentabilidade social, ambiental e econômica ocorra dentro dessas áreas, sob pena de argumentos que condenam a possibilidade de conciliação homem-natureza prevaleçam.

Revista de Gestão Social e Ambiental - RGSA, São Paulo, v. 6, n. 1, p. 53-69, jan./abril 2012. 


\section{REFERÊNCIAS}

Almeida, M.W.B. (2004). Direitos à floresta e ambientalismo: seringueiros e suas lutas. Revista Brasileira de Ciências Sociais, 19(55), 33-52.

Alegretti, Helena (1997). Ambientalismo político y reforma agrária: de Chico Mendes al movimiento de los sien tierra. Nueva Sociedad, n. 150, 57-68.

(2008). A Construção social de políticas públicas. Chico Mendes e o Movimento dos Seringueiros. Revista Desenvolvimento e Meio Ambiente, n. 18, 39-59.

Amazonas, M. de C. (2002). Economia ambiental neoclássica e desenvolvimento sustentável. In: NOBRE, Marcos; Desenvolvimento sustentável: a institucionalização de um conceito. Brasília: Ibama, 107 - 146.

Bardin, L (2004). Análise de conteúdo. (3ª ed.) Lisboa: Edições 70.

Becker, B.K (1994). Amazônia. São Paulo: Editora Ática.

Boserup, E (1991). Causes and effects of disequilibria in food production. Recuperado em 27 de setembro de 2009, de:

<http://horizon.documentation.ird.fr/exldoc/pleins_textes/pleins_textes_7/carton07/34444.pdf>.

Cavalcanti, F. C (2002). da S. A política ambiental na Amazônia: um estudo sobre as reservas extrativistas. Tese (Doutoramento em Economia). Instituto de Economia da UNICAMP.

Cavalcanti, Clóvis (2010). Concepções da economia ecológica: suas relações com a economia dominante e a economia ambiental. Estudos Avançados, 24 (68), 53-67.

Colchester, M (2000). Resgatando a natureza: comunidades tradicionais e modos de vida. In: Diegues, A. C. S. (Org). Etnoconservação: novos rumos para a proteção da natureza nos trópicos. São Paulo: Hucitec, 2000.

Constanza, R. (1991). Ecological economics: the science and management of sustainability. New York : Columbia university Press.

Fao (1999). Towards a harmonized definition of non-wood forest products. Unasylva, 50, 50(198), Recuperado em: 10 de abril de 2010, de: <www.fao.org/docrep/x2450e/x2450e00.htm .

Freitas, H.M.R. de, Moscarola, J.(2010). Pelo resgate de alguns princípios da análise de conteúdo: aplicação prática qualitativa em marketing. Recuperado em 28 de setembro de 2010, de: http://www.sphinxbr.com.br .

Gladwin, T.N., Kennelly, J.J. And Krause, T.S (1995). Shifting paradigms for sustainable development: implications for management theory and research. Academy of Management Review, 20(4), 874-907.

Gonçalves, C.W.P. (2001). Amazônia, Amazônias. São Paulo: Contexto. 
(2003). Geografando nos varadouros do mundo: da territorialidade (o seringal) à territorialidade seringueira (a Reserva Extrativista). Brasília: Ibama.

GTA (2008). O fim da floresta? A devastação das unidades de conservação e terras indígenas no Estado de Rondônia. Grupo de Trabalho Amazônico - GTA, Regional Rondônia.

Homma, A.K. (2000). Amazônia: os limites da opção extrativa. Ciência Hoje, 27(159).

(2008). Extrativismo, biodiversidade e biopirataria na Amazônia. Texto para discussão. Brasília, DF : Embrapa Informação Tecnológica.

IIED (2001). International Institute of Environment and Development. Annual Report (2000). Recuperado em 22 de março de 2001, de: <http://www.iied.org/>.

Imazon - Instituto do Homem e Meio Ambiente da Amazônia (2008). Pesquisa Regional sobre o manejo de produtos florestais não-madeireiros na Amazônia. Relatório Técnico Parcial. Sebrae/AC - Contrato n ${ }^{\circ}$ 10/2008. Belém/PA: Imazon.

Kemp, R., Martens, P.(2007). Sustainable development: how to manage something that is subjective and never can be achieved? Sustainability: Science, Practice, \& Policy, 3(2).

Martinez-Alier, J. (2007). O ecologismo dos pobres: conflitos ambientais e linguagens de valoração. São Paulo: Contexto.

Mebratu, D. (1998). Sustainability and sustainable development: historical and conceptual review. Environ Impact Asses Rev, (18), 493-520.

Meadows, D.H. et al. (2007). Limites do crescimento - atualização de 30 anos. Rio de Janeiro: Qualitymark.

Olmos, Fábio (2007). As reservas extrativistas são unidades de conservação? Recuperado em 2 de maio de 2009, de: http://www.oeco.com.br/todos-os-colunistas/44-fabio-olmos/16765>.

Pádua, M.T.J. (2007). Instituto Chico Mendes. O ECO. 2007. Recuperado em 18 de junho de 2008, de: <http://www.oeco.com.br/todos-os-colunistas/36-maria-tereza-jorge-padua/16297oeco_21814>..

Nobre, M., Amazonas, M. de C (2002). Desenvolvimento sustentável: a institucionalização de um conceito. Brasília: Ibama.

Pepper, D.(2000). Ambientalismo moderno. Coleção Perspectivas Ecológicas. Lisboa: Instituto Piaget.

Patterson, M.(2002). Headline indicators for tracking progress to sustainability in New Zealand. New Zealand: Ministry for Environment, ISBN 0-478-24057-0, ME number 429.

Portal do extrativismo (2009). Neoextrativismo e o agroextrativismo. Recuperado em 9 de abril de 2009, de: <http://www.florestavivaextrativismo.org.br/>.

Pearce, D. et al. (1993). Environmental economics. Baltimore: The Johns Hopkins University Press. 
Rego, J.F.do (1999). Amazônia: do extrativismo ao neoextrativismo. Revista Ciência Hoje. Recuperado em junho de 2008, de:

http://cienciahoje.uol.com.br/materia/resources/files/chmais/pass/ch147/opiniao.rtf.

Santilli, J.(2005). Sócio-ambientalismo e novos direitos: proteção jurídica à diversidade biológica e cultural. São Paulo: Peirópolis.

Valadão, J. de A., Siena, O. (2010). Contribuições dos Centros Familiares de Formação por Alternância para o desenvolvimento rural sustentável. RGSA-Revista de Gestão Social e Ambiental, 4(1), 52-791.

Veiga, J. E. da (2006). Meio ambiente e desenvolvimento. São Paulo: SENAC. (2007). A emergência socioambiental. São Paulo: Senac. (2008). Desenvolvimento sustentável: o desafio do século XXI. ( $3^{\mathrm{a}}$ ed.) Rio de Janeiro: Garamond.

WCED. World Commission on Environment and Development (1987). Our common future.

Zapparoli, I.D. et al (Ago 2010). A relação entre desenvolvimento sustentável empresarial e a gestão ambiental corporativa: análise do caso do Parque Estadual Mata Dos Godoy em Londrina/PR. RGSA - Revista de Gestão Social e Ambiental, Maio -4(2), 96-117.

Data do recebimento do artigo: 07/07/2011

Data do aceite de publicação: 01/04/2012 